ARTICLE

Received 19 May 2013 | Accepted 14 Oct 2013 | Published 12 Nov $2013 \quad$ DOl: 10.1038/ncomms3766

\title{
Hydrogen-atom-mediated electrochemistry
}

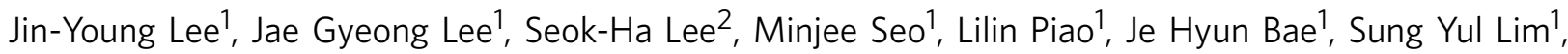
Young June Park ${ }^{2} \&$ Taek Dong Chung ${ }^{1}$

Silicon dioxide thin films are widely used as dielectric layers in microelectronics and can also be engineered on silicon wafers. It seems counterintuitive that electrochemical reactions could occur on such an insulator without relying on tunnelling current. Here we report electrochemistry based on electron transfer through a thin insulating layer of thermally grown silicon dioxide on highly $\mathrm{n}$-doped silicon. Under a negative electrical bias, protons in the silicon dioxide layer were reduced to hydrogen atoms, which served as electron mediators for electrochemical reduction. Palladium nanoparticles were preferentially formed on the dielectric layer and enabled another hydrogen-atom-mediated electrochemistry, as their surfaces retained many electrogenerated hydrogen atoms to act as a 'hydrogen-atom reservoir' for subsequent electrochemical reduction. By harnessing the precisely controlled electrochemical generation of hydrogen atoms, palladium-copper nanocrystals were synthesized without any surfactant or stabilizer on the silicon dioxide layer.

\footnotetext{
${ }^{1}$ Department of Chemistry, Seoul National University, Seoul 151-747, Korea. ${ }^{2}$ Department of Electrical and Computer Engineering, Seoul National University, Seoul 151-744, Korea. Correspondence and requests for materials should be addressed to T.D.C. (email: tdchung@snu.ac.kr).
} 
$\mathrm{P}$ recise control of electrochemical reactions on dielectric layers is a key issue that has been increasingly studied in recent years, because it would enable patterned circuits, stacks of thin films and various nanoparticles (NPs) to be fabricated on dielectric layers by direct electroplating. Although electrochemistry on dielectric layers has the potential to offer new fundamental methodologies in various fields such as the semiconductor industry, energy conversion, sensors, catalysts and supercapacitors, there have been relatively few studies on this topic, mainly because it is counterintuitive that electrochemical reactions could occur on dielectric layers, that is, insulators. In fact, electrochemistry through insulators such as glass ${ }^{1}$, metal oxide $^{2,3}$, organic monolayers ${ }^{4}$ and rubbed Teflon ${ }^{5}$ has been investigated. Previous studies have reported on electrochemistry through amorphous glass films ${ }^{1}$, which have many pores that permit the penetration of redox species and ions. Because of the permeability of many chemical species, no electron mediator was required to be in the glass membrane for a faradaic reaction. A silicon $(\mathrm{Si})$ electrode modified with an organic monolayer is another example that has been intensively investigated over the past decades. The reproducible fabrication of stable and sufficiently thick dielectric layers has been found to be crucial for informative and practical systems. Silver (Ag) NPs were electrodeposited on aluminum ( $\mathrm{Al}$ ) oxide at $-9 \mathrm{~V}$ (ref. 3) and the direct electrochemical reduction ${ }^{2}$ of $\mathrm{TiO}_{2}$ to $\mathrm{Ti}$ was performed at $950^{\circ} \mathrm{C}$. Rubbed Teflon was also adopted as an insulator on which metal was deposited ${ }^{5}$. Although such studies have suggested new approaches to introducing electrochemistry to insulating materials (dielectrics), there are still challenges to adapting these approaches to practical applications, including the permeability, reproducibility, temperature and controllability of the electrochemical reaction. More importantly, only a limited number of studies have investigated electrochemistry processes that occur at the dielectric layer. In this work, we introduced thermally grown silicon dioxide $\left(\mathrm{SiO}_{2}\right)$, a dense and stable dielectric layer, and explored the novel phenomena that could be observed in this electrochemical system.

Thermal $\mathrm{SiO}_{2}$ is a dielectric material used for conventional metal/insulator/metal capacitors ${ }^{6}$, and $\mathrm{SiO}_{2}$ films are widely used as gate insulators of metal/oxide/semiconductor (MOS) devices ${ }^{7}$, in which the field-induced drift of protons to the $\mathrm{Si} / \mathrm{SiO}_{2}$ interface and their interactions with electrons can create hydrogen $(\mathrm{H})$ atoms at the interface ${ }^{8,9}$. Shkrob et al. ${ }^{10}$ demonstrated that protons were reduced to generate mobile $\mathrm{H}$ atoms in $\mathrm{B}_{2} \mathrm{O}_{3}$ glasses at room temperature. Energy calculations revealed that $\mathrm{H}$ atoms in $\mathrm{SiO}_{2}$ are isolated by themselves without a strong interaction with oxygen $\left(\mathrm{O}_{2}\right)$ or $\mathrm{Si}$ atoms. $\mathrm{H}$ atoms reside in interstitial sites $\sim 2.0 \AA$ away from the nearest $\mathrm{O}_{2}$ atoms and do not disturb the surrounding lattice ${ }^{11}$. Schrauben et al. ${ }^{12}$ provided evidence for $\mathrm{H}$ atom transfer through reduced $\mathrm{TiO}_{2}$ and $\mathrm{ZnO}$ NPs in solution using two $\mathrm{H}$ abstractors, namely, 2,4,6-tri-tert-butylphenoxyl radical $\left({ }^{\mathrm{t}} \mathrm{Bu}_{3} \mathrm{ArO} \bullet\right)$ and 2,2,6,6-tetramethyl-piperidin-1-yl-oxyl. Revesz $^{13}$ studied on an electrolyte/oxide/Si (EOS) system to determine the concentration of certain active $\mathrm{H}$-bearing species in the oxide.

The highly $\mathrm{n}$-doped $\mathrm{Si}$ /thermal $\mathrm{SiO}_{2}$ thin layers in an aqueous electrolyte considered in this work represent an EOS system suitable for producing $\mathrm{H}$ atoms electrochemically by finely tuning the applied potential bias and $\mathrm{pH}$ of the solution. The $\mathrm{SiO}_{2}$ thin film, which is thermally grown on highly $\mathrm{n}$-doped $\mathrm{Si}$ (the fabrication method and properties are described in detail in Methods and the Supplementary Information), has a highly dielectric structure with minimal defects. Therefore, it permits both the selective migration of protons and the diffusion of electrogenerated $\mathrm{H}$ atoms ${ }^{9}$ in the middle of the electrical potential gradient. This result suggests that $\mathrm{H}$ atoms in the EOS system could be used as electron mediators on dielectric oxide layers acting as 'chemical electrodes' for electrochemical reactions. Free $\mathrm{H}$ atoms are theoretically very strong reducing agents $(-2.106 \mathrm{~V}$ versus normal hydrogen electrode $)^{14}$. In the proposed system of highly n-doped $\mathrm{Si} /$ thermal $\mathrm{SiO}_{2}$ thin layers, the reducing power of $\mathrm{H}$ atoms in $\mathrm{SiO}_{2}$ should not be as strong as that of freestanding $\mathrm{H}$ atoms. However, the well-ordered $\mathrm{SiO}_{2}$ structure provides a remarkably stable and inert environment. $\mathrm{H}$ atoms in titanium dioxide $\left(\mathrm{TiO}_{2}\right)$ and zinc oxide $(\mathrm{ZnO})$ are strongly bound and act as a dopant but weakly interact with the neighbouring oxygen atoms in $\mathrm{SiO}_{2}$ (refs 10,15). Thermally grown $\mathrm{SiO}_{2}$ is not expected to modify the chemical properties of the interstitial $\mathrm{H}$ atoms to the same degree as $\mathrm{TiO}_{2}$ (ref. 11) and $\mathrm{ZnO}$ (ref. 16). Therefore, in the proposed system, electrogenerated $\mathrm{H}$ atoms would serve as sufficiently strong reducing agents to reduce most reducible species in solution. Next, metal precursors could be electroplated by $\mathrm{H}$ atoms on the thermal $\mathrm{SiO}_{2}$ surface to potentially form the corresponding metal NPs. This process could offer important inspiration for many interesting applications in that various metal NPs adsorbed on oxide surfaces are widely used for energy technology, pollution prevention and environmental clean-up efforts ${ }^{17,}$. 8 . In particular, $\mathrm{SiO}_{2}$ is commonly used as an inert support for heterogeneous catalysts.

Compared with chemical reduction, electrochemical methods enable fine and easy control by electronic devices and primarily require no reducing agents because of the direct injection of electrons ${ }^{19}$. Therefore, electroplating has been considered as an alternative method for the cost-effective and stabilizer-free NP preparation. However, long-term electrochemical operation requires appropriate electrodes that must be safely free from passivation to continue providing electrons for sustainable faradaic reactions. Many electrodes are subject to deactivation, which is mostly caused by the irreversible adsorption of adsorptive intermediates and/or the deterioration of electrode materials by reactive species.

Herein, we report electron transfer through a thin insulating layer of the 6-nm-thick thermal $\mathrm{SiO}_{2}$ on highly $\mathrm{n}$-doped silicon $\left(\mathrm{n}^{+}-\mathrm{Si}\right)$, leading to unprecedented electrochemistry on the dielectric surface. Under a negative electrical bias, protons from the solution media migrate into the silicon dioxide layer and produce significant cathodic current. The asymmetric voltammograms from the proposed system suggest electrogeneration of $\mathrm{H}$ atoms as electron mediators for electrochemical reduction at the interface between the dielectric surface and solution. By precisely tuning the voltammetric conditions, palladium $(\mathrm{Pd})$-copper $(\mathrm{Cu})$ nanocrystals (NCs) are synthesized without any surfactant or stabilizer, and both $\mathrm{O}_{2}$ and carbon dioxide $\left(\mathrm{CO}_{2}\right)$ are electrochemically reduced on the $\mathrm{SiO}_{2}$ layer.

\section{Results}

$\mathrm{SiO}_{2}$ layers in the EOS system. The thermally grown $\mathrm{SiO}_{2}$ considered in this work has an exact stoichiometric composition $^{20}$. Supplementary Fig. S1 presents high-resolution transmission electron microscopy (HRTEM) cross-sectional images of the high $\mathrm{n}^{+}-\mathrm{Si} / \mathrm{SiO}_{2}$ (6-nm thick). A compact $\mathrm{SiO}_{2}$ layer was uniformly formed on Si; this layer was very stable as demonstrated by the tests of breakdown voltage and metal electroplating (Supplementary Figs S2 and S3; Supplementary Note 1).

The $\mathrm{n}^{+}-\mathrm{Si} / \mathrm{SiO}_{2}$ immersed in an aqueous solution was used as the working electrode to investigate the electrochemistry in this system, as illustrated in Fig. 1. The linear sweep voltammogram ( $i-V$ curve) obtained in the proposed EOS system using the $\mathrm{n}^{+}$ $-\mathrm{Si} / \mathrm{SiO}_{2}$ electrode demonstrates that the 6-nm-thick thermal $\mathrm{SiO}_{2}$ clearly differed from the native $\mathrm{SiO}_{\mathrm{x}}$ on $\mathrm{n}^{+}-\mathrm{Si}$ (Supplementary 


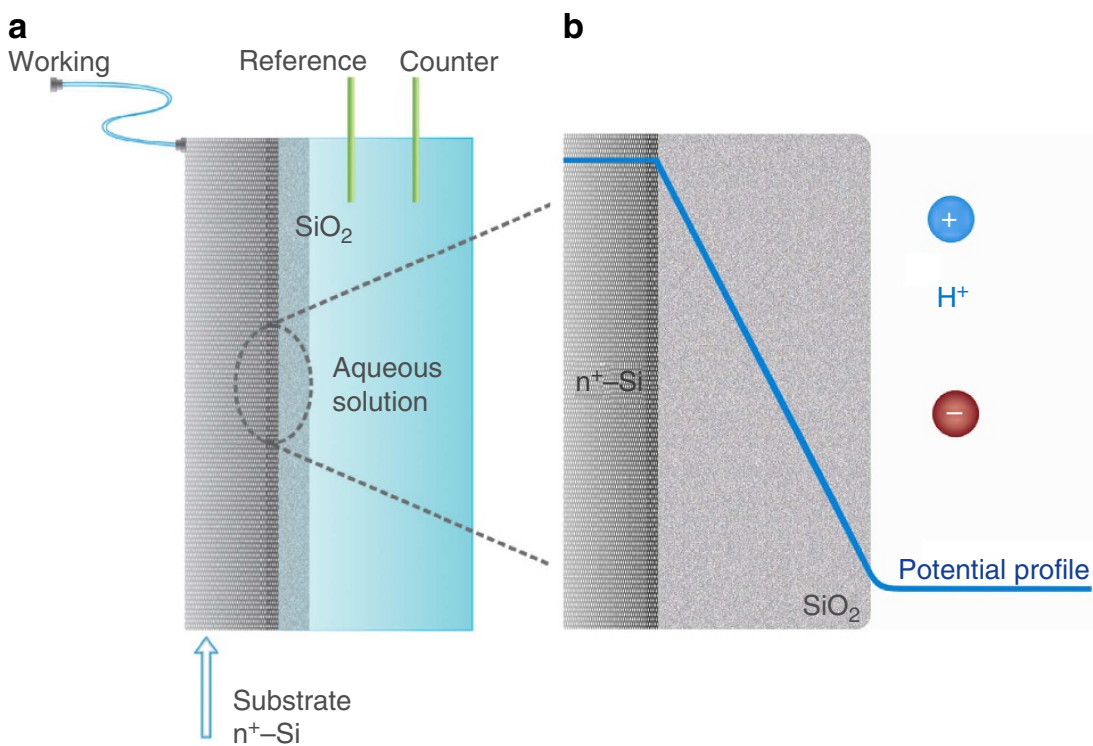

Figure 1 | Schematic view of the electrochemical experiment. (a) Experimental system and (b) schematic representation of the electrical potential profile across highly $\mathrm{n}$-doped $\mathrm{Si}\left(\mathrm{n}^{+}-\mathrm{Si}\right) /$ thermal $\mathrm{SiO}_{2}$ /aqueous electrolyte.

Fig. S4). Compared with the native $\mathrm{SiO}_{\mathrm{x}}$ layer, the structure of the thermal $\mathrm{SiO}_{2}$ is sufficiently dense and uniform for the background current to be negligible, providing a reliable system for electrochemical study.

In previous studies, the electrical potential distribution across the $\mathrm{Si} / \mathrm{SiO}_{2}$ interface in an EOS system was not significantly different from that in a MOS system ${ }^{21}$. In contrast to the solution in an MOS configuration, the solution in an EOS system acts as an infinite source of ions that can be polarized near the oxide surface upon the application of an electric field as long as the dielectric layer is sufficiently thin to incompletely isolate the conducting $\mathrm{Si}$ phase from the solution, in electrical terms ${ }^{7}$. However, the applied electrical potential still drops mainly across the oxide layer because of its high resistance of $10^{7} \Omega \mathrm{cm}^{2}$, for the thermally grown 6-nm-thick $\mathrm{SiO}_{2}$ layer on $\mathrm{n}^{+}-\mathrm{Si}$, as measured by impedance analysis (Supplementary Note 2). The electrical potential drop at the 6 -nm-thick $\mathrm{SiO}_{2}$ layer was $2 \times 10^{5}$ times greater than that at the $\mathrm{SiO}_{2}$ /solution interface in this EOS system (Supplementary Fig. S5). Therefore, the potential difference at the interface between $\mathrm{SiO}_{2}$ and the solution is negligible compared with the entire applied bias.

Electron transfer through the $\mathrm{SiO}_{2}$ dielectric layer. Figure 2a presents the cyclic voltammograms recorded using an $n^{+}-{ }_{-} \mathrm{Si} / \mathrm{SiO}_{2}$ electrode and the comparison of these voltammograms with that obtained using a glassy carbon (GC) electrode, in $0.1 \mathrm{M}$ potassium phosphate buffer solution at $\mathrm{pH} 3$. The electrochemical oxidation of $\mathrm{Ru}\left(\mathrm{NH}_{3}\right)_{6}^{2+}$ at the $\mathrm{n}^{+}-\mathrm{Si} / \mathrm{SiO}_{2}$ required a considerably higher overpotential than the GC electrode. The onset potential was observed at approximately $+3.2 \mathrm{~V}$ (versus $\mathrm{Ag} / \mathrm{AgCl}$ ), and the current increased gradually as the potential increased in the positive direction. In contrast, the overpotential for $\mathrm{Ru}\left(\mathrm{NH}_{3}\right)_{6}^{3}+$ reduction was far lower than expected from the oxidation results in the same system. The faradaic current for reduction sensitively responded to the electrical potential bias, despite the compact dielectric layer of thermally grown $\mathrm{SiO}_{2}$. In addition, Fig. 2b,c demonstrates that the onset potential of an $\mathrm{n}^{+}-\mathrm{Si} / \mathrm{SiO}_{2}$ electrode systematically depended on the $\mathrm{pH}$ of the aqueous electrolyte in the cathodic regime, whereas no $\mathrm{pH}$ dependence was observed in the anodic region. The asymmetric voltammogram in Fig. 2a strongly implies that there are electrochemically reducible species inside the $\mathrm{SiO}_{2}$ layer, preferentially taking up electrons from the highly doped Si phase.

These electrochemically reducible species can be identified from the following process. First, the cathodic onset potential of the $\mathrm{n}^{+}-\mathrm{Si} / \mathrm{SiO}_{2}$ electrode in an aprotic organic electrolyte, such as acetonitrile, was observed at approximately $-2.2 \mathrm{~V}$ (versus $\mathrm{Ag} /$ $\mathrm{Ag}^{+}$; Supplementary Fig. S6). The cathodic current disappeared without a proton. Second, the behaviour in acetonitrile follows the Fowler-Nordheim tunnelling (Supplementary Fig. S7), which is similar to MOS systems ${ }^{22}$. When a small amount of proton sources, $\mathrm{HClO}_{4}$, was added to the solution, the cathodic current began to flow at a more positive value of approximately $-1.2 \mathrm{~V}$, whereas the background current was negligible in the same potential range (Supplementary Fig. S8). The proton sources clearly caused the system to deviate from the Fowler-Nordheim tunnelling model (Supplementary Note 3), revealing that the proposed system cannot be explained by a simple direct tunnelling model. Third, the thermal $\mathrm{SiO}_{2}$ layer in this system completely blocks permeation of all chemical species, including $\mathrm{Ru}\left(\mathrm{NH}_{3}\right)_{6}^{2}+13+$ ions and electrolytes, except protons, which can diffuse through the $\mathrm{SiO}_{2}$ interfacial plane ${ }^{23}$ and reversibly migrate back and forth in response to an external electric field ${ }^{24}$. This evidence unequivocally supports the conclusion that the cathodic currents in the linear sweep voltammograms in Fig. 2 were attributed to protons, which can migrate into the $\mathrm{SiO}_{2}$ layer and be electrochemically reduced (Supplementary Note 4).

Figure $2 \mathrm{a}$ reveals that the current in the forward scan in the negative potential region was smaller than that in the reverse scan. This result again demonstrates that the thermal $\mathrm{SiO}_{2}$ layer in the proposed system is not a simple insulator through which a tunnelling current predominantly flows. During the period in which a negative potential was applied, protons accumulated in the $\mathrm{SiO}_{2}$ layer and were electrochemically reduced to $\mathrm{H}$ atoms. This result is ensured by a comparison of the consecutive scans in linear sweep voltammetry. The onset potential of the second scan, which was performed immediately after the first scan, shifted in the positive direction and the cathodic current increased (Supplementary Fig. S9). The $\mathrm{H}$ atoms remaining inside the $\mathrm{SiO}_{2}$ layer, which were generated during the previous scan, could relay electrons to the protons originating from the solution via 

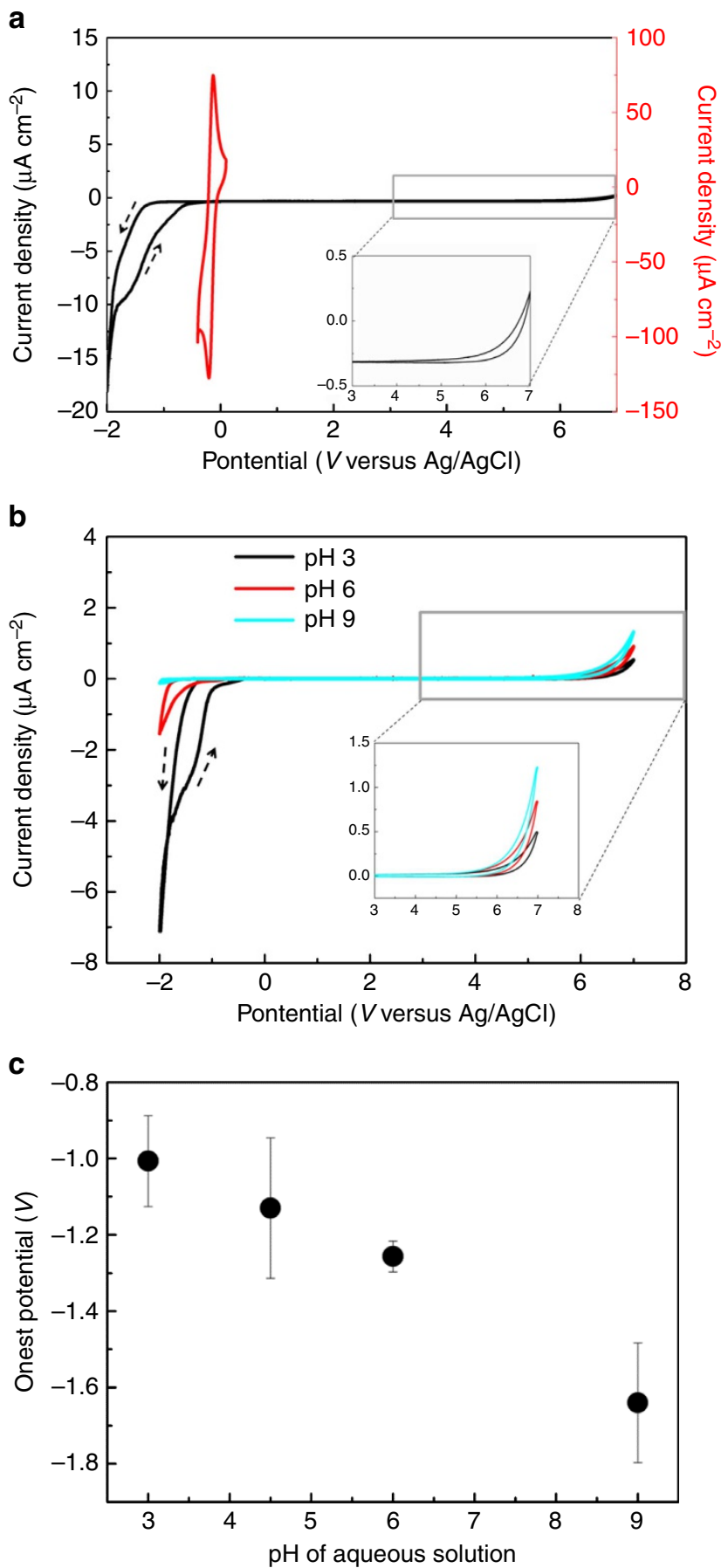

Figure 2 | Electrochemistry of the proposed EOS system. (a) Cyclic voltammograms (CVs) of the $\mathrm{n}^{+}-\mathrm{Si} / \mathrm{SiO}_{2}$ electrode (black) and GC electrode (red) were recorded at room temperature in an $\mathrm{N}_{2}$-purged solution of $1 \mathrm{mM} \mathrm{Ru}\left(\mathrm{NH}_{3}\right)_{6} \mathrm{Cl}_{3}+\mathrm{Ru}\left(\mathrm{NH}_{3}\right)_{6} \mathrm{Cl}_{2}+0.1 \mathrm{M}$ potassium phosphate solution at $\mathrm{pH} 3$ with a scan rate of $10 \mathrm{mVs}^{-1}$. (b) $\mathrm{CV}$ curves of the $\mathrm{n}^{+}-\mathrm{Si} / \mathrm{SiO}_{2}$ (6-nm thick) electrode were obtained in $0.1 \mathrm{M}$ phosphate buffer at pH 3 (black), pH 6 (red) and pH 9 (bright blue). The insets in a and $\mathbf{b}$ present the enlarged portion of the $\mathrm{CV}$ for the anodic potential at the $\mathrm{n}^{+}-\mathrm{Si} / \mathrm{SiO}_{2}$ electrode. (c) The onset potential depending on the $\mathrm{pH}$ in $\mathbf{b}$. The onset potential was determined at the potential at which the current density is above $30 \%$ compared with the baselines. The voltammograms were obtained at $10 \mathrm{mVs}^{-1}$ at room temperature under $\mathrm{N}_{2}$.

homogeneous electron exchange. The onset potential was restored after leaving the electrode in a solution for $\sim 1 \mathrm{~h}$ without any electrical bias (Supplementary Fig. S9).
Figure $3 \mathrm{a}$ illustrates how the migration and reduction of protons in the $\mathrm{SiO}_{2}$ layer can enable the reduction of redox species without a direct tunnelling current despite the presence of the dense insulating $\mathrm{SiO}_{2}$ layer. The electrogenerated $\mathrm{H}$ atoms either directly serve as electron mediators or form $\mathrm{H}_{2}$ molecules at the $\mathrm{SiO}_{2}$ /solution interface.

Electrochemical reduction of $\mathrm{CO}_{2}$ and $\mathrm{O}_{2}$ in the EOS system. The $\mathrm{H}$-atom-mediated electrochemistry of this simple $\mathrm{n}^{+}-\mathrm{Si}$ / $\mathrm{SiO}_{2}$ /aqueous electrolyte system could be used for the electrochemical reduction of $\mathrm{CO}_{2}$ and $\mathrm{O}_{2}$, which involves strongly reactive or adsorptive intermediates. In particular, the reductive transformation of $\mathrm{CO}_{2}$ to fuels and commodity chemicals is one of the most important contemporary energy and environmental challenges. The initial step from $\mathrm{CO}_{2}$ to $\mathrm{CO}_{2}^{\circ-}$ has been reported to be rate limiting in many cases. Either the overpotentials are exceedingly high or the metal surface becomes deactivated by the intermediates ${ }^{25,26}$. The long-term stability of the electrodes is a crucial challenge in making electrochemical $\mathrm{CO}_{2}$ reduction economically feasible ${ }^{26}$. Figure $3 \mathrm{~b}$ demonstrates the $\mathrm{CO}_{2}$ reduction in this system. The product of $\mathrm{CO}_{2}$ reduction in this system was mainly formic acid at $-1.5 \mathrm{~V}$ (versus $\mathrm{Ag} / \mathrm{AgCl}$ ) in $\mathrm{CO}_{2}$-saturated aqueous solution at $\mathrm{pH} 3$ for longer than $4 \mathrm{~h} . \mathrm{H}$ atoms that were not used for $\mathrm{CO}_{2}$ reduction are expected to form molecular hydrogen. Both $\mathrm{O}_{2}$ and $\mathrm{CO}_{2}$ can be reduced in this system (Fig. 3c) without significant deterioration of the oxide structure by electrolysis over $1 \mathrm{~h}$.

Bimetallic NCs synthesized electrochemically on the $\mathrm{SiO}_{2}$ layer. The finely controllable $\mathrm{H}$-atom-mediated electrochemistry of the $\mathrm{n}^{+}-\mathrm{Si} / \mathrm{SiO}_{2}$ (6-nm thick)/aqueous electrolyte system was used for the electrodeposition of several types of metals. Direct electron tunnelling can reduce metal precursors on native silicon oxide, producing 1- to 2-nm-thick non-adherent powders that are readily washed off by rinsing ${ }^{27}$. In contrast, the Pd NPs (diameter of 10-40 nm) formed in this system were uniformly distributed on the oxide layer due to the reduction of $\mathrm{Pd}^{2+}$ ions to metallic Pd (Supplementary Fig. S10). The Pd NPs were anchored so strongly that very few were washed off by rinsing. $\mathrm{H}_{2}$ molecules are likely to prevent the initial $\mathrm{Pd}$ seeds from aggregating, resulting in immobilization ${ }^{28}$, and thus, $\mathrm{H}$ atoms, which are much stronger reducing agents, are assumed to have a pivotal role in the prompt reduction of $\mathrm{Pd}^{2}+$ ions. Thus, this system enables the single-step electrochemical fabrication of Pd NPs firmly adhered to the $\mathrm{SiO}_{2}$ layer in aqueous solution at room temperature without surfactants or stabilizers. Pd NPs prepared in this manner are expected to have application in hydrogen storage as catalysts on solid supports and as sensing devices ${ }^{29}$.

Metallic $\mathrm{Pd}$ is well known to retain $\mathrm{H}$ atoms on its surface. Once Pd NPs are formed on the $\mathrm{SiO}_{2}$ layer, the excess $\mathrm{H}$ atoms are predicted to be adsorbed on the surfaces of the Pd NPs spontaneously at room temperature. Even if $\mathrm{H}_{2}$ molecules are formed, they would be readily dissociated on the Pd surface ${ }^{29}$. Thus, the hydrogen-rich surfaces of the Pd NPs are expected to facilitate deposition of metals, such as $\mathrm{Cu}$, which otherwise do not adhere to the $\mathrm{SiO}_{2}$ surface 27 . The Pd NPs on the $\mathrm{SiO}_{2}$ surface in this system act as 'H-atom lagoons' that collect and store as many $\mathrm{H}$ atoms as they can on their surfaces, as demonstrated in Fig. 3d. Such a novel $\mathrm{H}$-atom lagoon leads to the subsequent electroplating of various metals, including bimetallic NCs.

Bimetallic NCs are of considerable interest because of their unique properties and potential applications ${ }^{30,31}$. H-atommediated electrochemistry employing $\mathrm{H}$-atom lagoons, such as those formed by Pd NPs on $\mathrm{SiO}_{2}$, can achieve facile bimetallic NC synthesis with a polyhedral alloy on an inert support. Figure $4 \mathrm{a}$ 
a
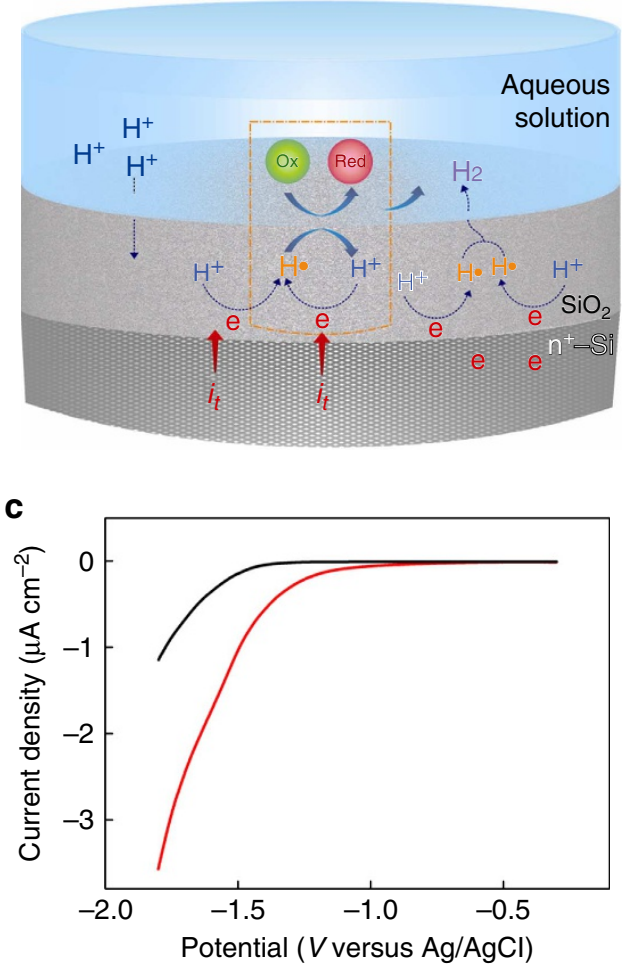

b

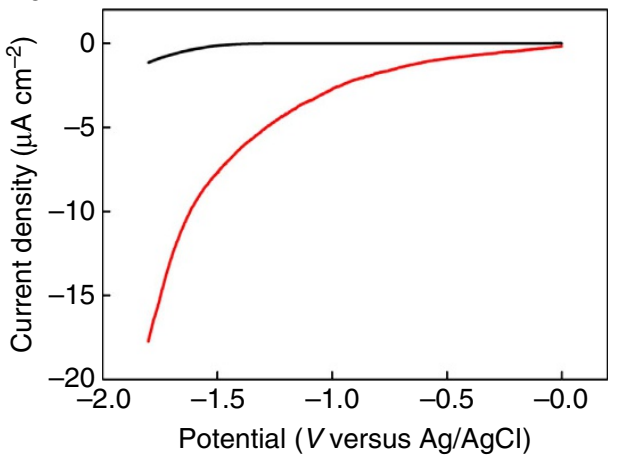

d

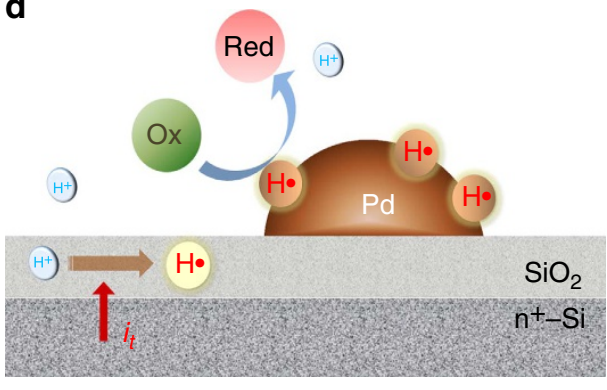

Figure 3 | $\mathbf{C O}_{\mathbf{2}}$ and $\mathbf{O}_{\mathbf{2}}$ reduction and Pd NPs acting as $\mathbf{H}$-atom lagoons. (a) Schematic view of the reactions in the proposed system: $\mathrm{H}$-atom-mediated electron transfer in $\mathrm{n}^{+}$-Si/thermally oxidized $\mathrm{SiO}_{2}$ /aqueous solution. Protons in the aqueous solution drift into the $\mathrm{SiO}_{2}$ layer and become $\mathrm{H}$ atoms by capturing electrons tunnelling through the $\mathrm{Si} / \mathrm{SiO}_{2}$ interface under a negative potential. (b) The linear sweep voltammogram of $\mathrm{n}^{+}-\mathrm{Si} /$ thermally oxidized $\mathrm{SiO}_{2}$ in black was obtained at room temperature in an $\mathrm{N}_{2}$-purged solution of $0.1 \mathrm{M}$ potassium phosphate at $\mathrm{pH}$ 3. The linear sweep voltammogram in red was obtained at room temperature in a $\mathrm{CO}_{2}$-saturated solution of $0.1 \mathrm{M}$ potassium phosphate at $\mathrm{pH}$ 3. (c) The linear sweep voltammogram of $\mathrm{n}^{+}$ - $\mathrm{Si}$ /thermally oxidized $\mathrm{SiO}_{2}$ in black was obtained at room temperature in an $\mathrm{N}_{2}$-purged solution of $0.1 \mathrm{M}$ potassium phosphate at $\mathrm{pH}$ 3. The linear sweep voltammogram in red was obtained at room temperature in an $\mathrm{O}_{2}$-saturated solution of $0.1 \mathrm{M}$ potassium phosphate at pH 3. (d) Schematic illustration of the $\mathrm{H}$-atom lagoon effect of $\mathrm{Pd} \mathrm{NPs}$ on $\mathrm{n}^{+}-\mathrm{Si} / \mathrm{SiO}_{2}$ (thermally oxidized) for the reduction of reducible species.

presents electron microscopic images of polyhedral $\mathrm{Pd}-\mathrm{Cu}$ bimetallic NCs consisting of octahedron (32\%), triangular prisms (38\%) and others (30\%). This study represents the first electrochemical shape-controlled synthesis of bimetallic NCs without any stabilizer or surfactant. Energy-dispersive spectroscopy (EDS) revealed that the electroplated $\mathrm{Pd}-\mathrm{Cu}$ bimetallic NCs were a $\mathrm{Pd}-\mathrm{Cu}$ mixed alloy (Supplementary Fig. S11). The TEM image and corresponding electron diffraction pattern of a single $\mathrm{Pd}-\mathrm{Cu} \mathrm{NC}$ in Fig. $4 \mathrm{f}$ indicate that the NC was a piece of a single crystal enclosed by $\{111\},\{200\}$ and $\{220\}$ facets. In addition to Pd-Cu NCs, Pd-Au NCs and Pd-Co $\mathrm{NCs}$ were also synthesized on a thin $\mathrm{SiO}_{2}$ layer at room temperature without the aid of a stabilizer or additive (Supplementary Figs S12 and S13).

\section{Discussion}

The remarkably low onset potential (Fig. 2a) for the cathodic reaction indicates that protons were reduced inside the $\mathrm{SiO}_{2}$ layer. Thus, the observed voltammetric results can be understood by a scenario in which an external electric field causes protons to migrate in the oxide layer ${ }^{24}$ and the protons are electrochemically reduced to produce $\mathrm{H}$ atoms $\mathrm{s}^{9,32}$ in a negative potential regime. Shkrob et al. ${ }^{10}$ suggested that electrons react with network-bound protons at $180-530 \mathrm{~K}$ to produce $\mathrm{H}$ atoms.

$$
\equiv \mathrm{Si}-(\mathrm{OH})^{+}-\mathrm{Si} \equiv+e \rightarrow \equiv \mathrm{Si}-\mathrm{O}-\mathrm{Si} \equiv+\mathrm{H} \cdot
$$

We applied a negative potential to an $\mathrm{n}^{+}-\mathrm{Si} / \mathrm{SiO}_{2}$ electrode in $0.1 \mathrm{M}$ potassium phosphate buffer solution at $\mathrm{pH} 3$ and acquired surface-enhanced Raman scattering (SERS) spectra from the $\mathrm{SiO}_{2}$ layer. The peak of the $\mathrm{Si}-\left(\mathrm{OH}^{+}\right)-\mathrm{Si}$ complex ${ }^{33}$ at $\sim 2,905 \mathrm{~cm}^{-1}$ was observed (Supplementary Fig. S14) in accordance with the suggested mechanism ${ }^{10}$. This observation confirms the permeation of protons into the $\mathrm{SiO}_{2}$ layer and supports the idea that $\mathrm{H}$ atoms can be generated because of proton reduction in the $\mathrm{SiO}_{2}$ layer under an external electric field.

The presence and role of $\mathrm{H}$ atoms as electron mediators in the $\mathrm{SiO}_{2}$ layer can be verified by independent voltammetric experiments using several redox-active species with different reduction potentials. Although redox-active species are characteristically reduced at different potentials on conventional conducting electrodes, such as GC and $\mathrm{Au}$, their reduction behaviour in this system exhibited no correlation with the reduction potentials of their own (not shown). This result cannot be explained by a direct tunnelling current.

The electrochemical reduction of iridium (Ir) precursors (Supplementary Fig. S15) provides additional evidence of the electrogeneration of $\mathrm{H}$ atoms in the $\mathrm{SiO}_{2}$ layer. Although the $\mathrm{Ir}$ precursors used in this study require a very negative potential or commensurately strong reducing agent to be reduced, metallic Ir NPs were electrodeposited on the $\mathrm{SiO}_{2}$ surface at a moderate potential bias of $-1.3 \mathrm{~V}$. Considering the monotonously linear and predominant drop of electrical potential across the $\mathrm{SiO}_{2}$ film (Fig. 1), it is unlikely that a direct tunnelling current is responsible for this result. The experiment indicated that the Ir precursors are not reduced by $\mathrm{H}_{2}$ molecules but may be reduced by $\mathrm{H}$ atoms 34,35 

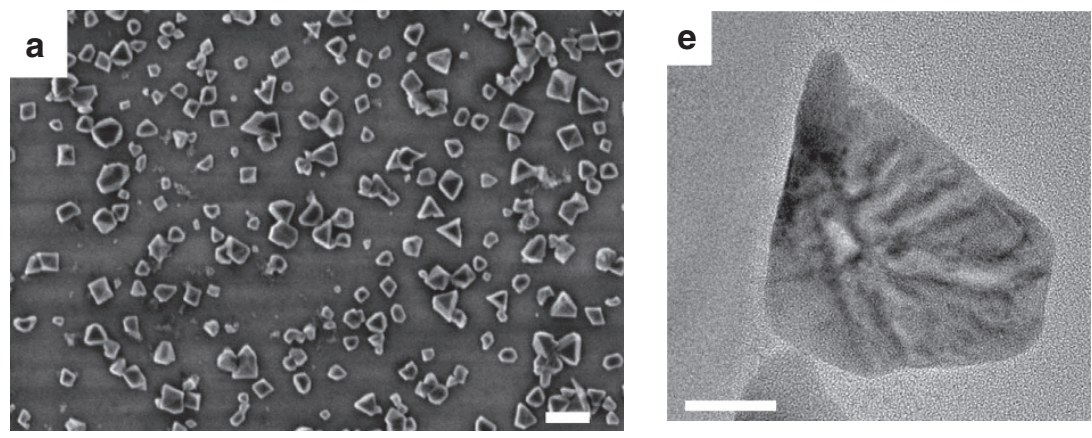

b
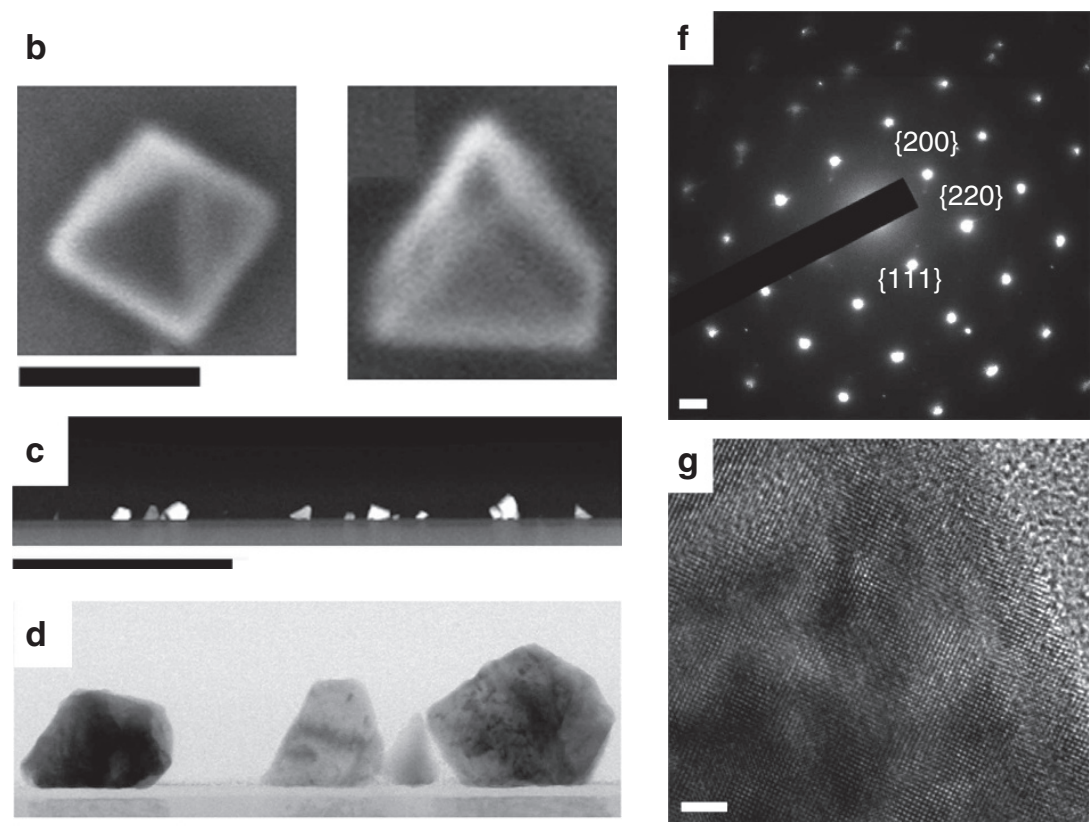

Figure 4 | Pd-Cu NCs. (a) FESEM image of Pd-Cu NCs prepared as follows. First, a constant potential of $-1.2 \mathrm{~V}$ was applied to $\mathrm{n}^{+}-\mathrm{Si} / \mathrm{SiO}_{2}$ for $30 \mathrm{~min}$

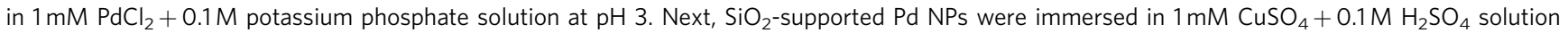
and a constant potential of $-1.3 \mathrm{~V}$ was applied for $30 \mathrm{~min}$. Scale bar, $200 \mathrm{~nm}$. (b) High-magnification FESEM image of Pd-Cu NCs prepared as in a. Octahedron-shaped Pd-Cu NCs (left), triangular-prism-shaped Pd-Cu NCs (right). Scale bar, $100 \mathrm{~nm}$. (c) High-angle annular dark field-scanning TEM image of $\mathrm{SiO}_{2}$-supported Pd-Cu NCs prepared as in a. Scale bar, $1 \mu \mathrm{m}$. (d) TEM image of Pd-Cu NCs. Scale bar, $100 \mathrm{~nm}$. (e) TEM image of Pd-Cu NCs. Scale bar, $20 \mathrm{~nm}$. (f) Electron diffraction pattern of NCs. Scale bar, $2 \mathrm{~nm}^{-1}$. (g) HRTEM image of a single Pd-Cu NC. Scale bar, $2 \mathrm{~nm}$.

In this study, we propose and investigate $\mathrm{H}$-atom-mediated electrochemistry in the system of $\mathrm{n}^{+}-\mathrm{Si}$ /thermal $\mathrm{SiO}_{2}$ /aqueous solution in which a thin and dense $\mathrm{SiO}_{2}$ layer acted as a protonselective membrane and reservoir of atomic $\mathrm{H}$. In voltammetry, the redox current was not linearly dependent on the external potential bias, and reduction occurred at a lower overpotential in proton-rich solutions compared with oxidation, resulting in asymmetric voltammetric behaviour. The experimental evidences unequivocally demonstrates that protons from the solution permeated into the $\mathrm{SiO}_{2}$ layer and were reduced to form $\mathrm{H}$ atoms by the uptake of electrons from the highly doped $\mathrm{Si}$ phase under a negative potential. The electrogenerated $\mathrm{H}$ atoms diffuse into the $\mathrm{SiO}_{2}$ layer and reduce the precursors, having the role of electron mediators. The suggested mechanism is in good agreement with the observed nonlinear and asymmetric voltammetric behaviour. The proposed $\mathrm{H}$-atom-mediated electrochemistry can be used to synthesize Pd NPs with an average size of 10-30 $\mathrm{nm}$ without using stabilizers or additives (Supplementary Fig. S10). More importantly, the Pd NPs on the $\mathrm{SiO}_{2}$ layer can act as a $\mathrm{H}$-atom lagoon for the facile nanofabrication of bimetallic $\mathrm{NCs}$ such as $\mathrm{Pd}-\mathrm{Cu}, \mathrm{Pd}-\mathrm{Au}$ and $\mathrm{Pd}-\mathrm{Co}$. In particular, the system in this study successfully demonstrated its potential for producing various metallic nanostructures, including $\mathrm{Pd}-\mathrm{Cu}$ bimetallic NCs, with such shapes as triangular prisms and octahedron on the $\mathrm{SiO}_{2}$ substrate. Both bimetallic NCs and monometallic NPs were synthesized on the $\mathrm{SiO}_{2}$ in the absence of any additive or stabilizer. H-atom-mediated electrochemistry will provide an impetus to the future fabrication of electronic circuits, sensory units and thin-film-based energy conversion devices on insulating layers.

\section{Methods}

Preparation of thermal oxidized $\mathrm{SiO}_{2}$. N-type $\left(\mathrm{n}^{+}-\mathrm{Si}\right)$, phosphorous-doped, $<100>$ oriented $\mathrm{Si}$ wafers with a resistivity as low as $0.005 \Omega \mathrm{cm}$ were obtained from STC (Japan). Highly n-doped $\mathrm{Si}$ with thermally oxidized $\mathrm{SiO}_{2}\left(\mathrm{n}^{+}-\mathrm{Si} / \mathrm{SiO}_{2}\right)$ was prepared via conventional thermal oxidation of highly doped $\mathrm{Si}$ wafers ( $<100>$, n-type, $0.005 \Omega \mathrm{cm}$ ). After cleaning with a mixture of $\mathrm{H}_{2} \mathrm{SO}_{4}$ and $\mathrm{H}_{2} \mathrm{O}_{2}$, the native oxide was stripped by HF dipping and the $200-\AA$-thick thermal oxide was produced at $850^{\circ} \mathrm{C}$ in a furnace with dry $\mathrm{O}_{2}$ blowing. Next, 200- $\AA$-thick thermal oxides were stripped again by HF dipping. Cleaning was repeated and the target 50 - or 60 - $\AA$-thick thermal $\mathrm{SiO}_{2}$ layer was formed at $850^{\circ} \mathrm{C}$ in a furnace with dry $\mathrm{O}_{2}$ blowing. The thermal $\mathrm{SiO}_{2}$ layers produced were uniformly flat. Ellipsometry and HRTEM (Supplementary Fig. S1) confirmed that the thicknesses of the thermal $\mathrm{SiO}_{2}$ layer on $\mathrm{Si}$ was $60 \AA$. 
Chemicals and electrochemical experiments. Before every experiment, the samples were degreased by sonication in acetone and isopropanol, and rinsed with methanol or deionized water. For back contact, the back side of the wafer sample was scratched with a diamond knife to remove the air-formed $\mathrm{SiO}_{2}$ film followed by smearing with a Ga-In eutectic. This surface was then pressed to a metal support. The ohmic nature of the contact was verified by electrical measurements.

After this procedure, the samples were pressed against the O-ring of an electrochemical cell, leaving $0.066 \mathrm{~cm}^{2}$ exposed to an aqueous solution of $0.1 \mathrm{M}$ potassium phosphate (Daejung Chemicals \& Metals Co., Ltd) in deionized water. A $\mathrm{pH}$ electrode (ROSS 8102, Orion) was used to adjust the $\mathrm{pH}$ of the aqueous solution for electrochemical measurement. The electrochemical experiments were performed at room temperature in a three-electrode electrochemical cell connected to a potentiostat (750, CHI Instruments, Inc.). $\mathrm{An} \mathrm{Ag} / \mathrm{AgCl}$ (in $3 \mathrm{M} \mathrm{NaCl}$, BAS Inc.) and Pt wire (diameter $0.5 \mathrm{~mm}$ ) were used as reference and counter electrodes, respectively. Cyclic voltammograms and linear sweep voltammograms were obtained with or without redox species after purging with $\mathrm{N}_{2}$ for $20 \mathrm{~min}$. Hexaammineruthenium (II) chloride $\left(\mathrm{Ru}\left(\mathrm{NH}_{3}\right)_{6} \mathrm{Cl}_{2}, \geq 99.9 \%\right.$ trace metal basis), hexaammineruthenium (III) chloride $\left(\mathrm{Ru}\left(\mathrm{NH}_{3}\right)_{6} \mathrm{Cl}_{3}, 98 \%\right)$ and Ir (III) chloride hydrate $\left(\mathrm{Ir}_{3} \mathrm{Cl} \cdot \mathrm{xH}_{2} \mathrm{O}, \geq 99.9 \%\right.$ trace metal basis) were purchased from SigmaAldrich for use as redox species.

For $\mathrm{CO}_{2}$ and $\mathrm{O}_{2}$ reduction, $\mathrm{Si}\left(\mathrm{n}^{+}-\mathrm{Si}\right) / \mathrm{SiO}_{2}$ (6-nm thick) was used as a working electrode; this electrode was exposed to $0.1 \mathrm{M}$ potassium phosphate buffer at $\mathrm{pH} 3$ after rinsing with deionized water. The aqueous solution was purged with $\mathrm{CO}_{2}$ or $\mathrm{O}_{2}$ gas for at least $20 \mathrm{~min}$. $\mathrm{An} \mathrm{Ag} / \mathrm{AgCl}$ (in $3 \mathrm{M} \mathrm{NaCl}$, BAS, Inc.) and Pt mesh were used as reference and counter electrodes, respectively. For $\mathrm{CO}_{2}$ reduction, after applying a constant potential of $-1.5 \mathrm{~V}$ (versus $\mathrm{Ag} / \mathrm{AgCl}$ ) to the working electrode for $4-8 \mathrm{~h}$, the solution was analysed using HPLC (Dionex, USA) at the National Instrumentation Center for Environmental Management of Seoul National University.

SERS on $\mathbf{n}^{+}-\mathbf{S i} / \mathbf{S i O}_{2}$ in the EOS system. The 11-mercaptoundecanol-modified gold microshell was used for SERS monitoring ${ }^{36}$. The Raman spectra were obtained using a homemade Ramboss Micro-Raman system spectrometer with a TE cooled $\left(-60^{\circ} \mathrm{C}\right)$ charged-coupled device camera $(1,024 \times 128$ pixels $)$. The $632.8 \mathrm{~nm}$ line from a He-Ne laser (LASOS Lasertechnik GmbH, USA) was employed as an excitation source and focused through a $\times 50$ objective for in situ electrochemical SERS experiments. The grating $\left(1,200\right.$ and 1,800 grooves $\left.\mathrm{mm}^{-1}\right)$ and slit provided a spectral resolution of $4 \mathrm{~cm}^{-1}$. The spectrometer was calibrated with the Raman bands of a silicon wafer at $520 \mathrm{~cm}^{-1}$ and indene at $730.4,1,018.3,1,205.6,1,552.7$ and $1,610.2 \mathrm{~cm}^{-1}$.

Ir deposition catalysed by $\mathbf{H}$ atoms present on the $\mathrm{SiO}_{2}$ surface. The $\mathrm{n}^{+}-\mathrm{Si} /$ $\mathrm{SiO}_{2}$ (6-nm thick) electrode was immersed in an $\mathrm{N}_{2}$-purged solution of iridium (III) chloride hydrate and a constant potential of $-1.3 \mathrm{~V}$ was applied to the electrode. The presence of Ir particles on $\mathrm{n}^{+}-\mathrm{Si} / \mathrm{SiO}_{2}$ was confirmed by fieldemission scanning electron microscopy (FESEM) and X-ray photoelectron spectroscopy. Supplementary Fig. S11 presents the deposition of Ir, and X-ray photoelectron spectroscopy provided data characteristic of metallic Ir, namely Ir $4 \mathrm{f}_{7 / 2}$ and Ir $4 f_{5 / 2}$ peaks at 61.0 and $63.9 \mathrm{eV}$, respectively.

Formation of $\mathbf{N C s}$ or $\mathbf{N P s}$ on $\mathbf{S i O}_{\mathbf{2}}$. Palladium (II) chloride $\left(\mathrm{PdCl}_{2}, \geq 99.9 \%\right)$, potassium gold (III) chloride $\left(\mathrm{KAuCl}_{4}, 98 \%\right)$ and cobalt sulfate hydrate $\left(\mathrm{CoSO}_{4} \cdot \times \mathrm{H}_{2} \mathrm{O}, \geq 99.9 \%\right.$ trace metal basis) were purchased from Sigma-Aldrich. Copper sulphate $\left(\mathrm{CuSO}_{4}\right)$ was purchased from Junsei Chemicals Co., Ltd. Deposition of Pd NPs on ${ }^{+}-\mathrm{Si}^{-} \mathrm{SiO}_{2}$ (6-nm thick) was performed in a conventional three-electrode cell with an $\mathrm{Ag} / \mathrm{AgCl}$ electrode $(3 \mathrm{M} \mathrm{NaCl}$, BAS Inc.) and $\mathrm{Pt}$ wire (diameter of $0.5 \mathrm{~mm}$ ) as the reference and counter electrodes, respectively. All potentials refer to the $\mathrm{Ag} / \mathrm{AgCl}$ reference electrode. The NPs and NCs were electrochemically synthesized in $0.1 \mathrm{M}$ potassium phosphate buffer at $\mathrm{pH} 3$ in an $\mathrm{N}_{2}$ environment immediately after purging the solution with $\mathrm{N}_{2}$ gas for $20 \mathrm{~min}$ at room temperature.

To deposit Pd NPs on the $\mathrm{SiO}_{2}$ surface, an aqueous solution composed of $0.2-1 \mathrm{mM} \mathrm{PdCl}{ }_{2}$ in $0.1 \mathrm{M}$ potassium phosphate buffer at $\mathrm{pH} 3$ was prepared and a constant potential of $-1.2 \mathrm{~V}$ or $-1.5 \mathrm{~V}$ (versus $\mathrm{Ag} / \mathrm{AgCl}$ ) was applied to the $\mathrm{n}^{+}$ $-\mathrm{Si} / \mathrm{SiO}_{2}$. After $\mathrm{Pd}$ deposition on the $\mathrm{SiO}_{2}$ surface, other metals, including $\mathrm{Cu}, \mathrm{Au}$ and $\mathrm{Co}$, were deposited on $\mathrm{n}^{+}-\mathrm{Si}_{\mathrm{S}} \mathrm{SiO}_{2}$-supported $\mathrm{Pd} \mathrm{NP}$ electrodes to determine whether Pd-based bimetallic fabrication occurred. For Pd-Cu bimetallic NCs, a $1 \mathrm{mM} \mathrm{CuSO}$ aqueous solution in $0.1 \mathrm{M}$ potassium phosphate buffer at $\mathrm{pH} 3$ was prepared and the constant potential of $-1.3 \mathrm{~V}$ (versus $\mathrm{Ag} / \mathrm{AgCl}$ ) was applied to the $\mathrm{n}^{+}-\mathrm{Si}_{/} \mathrm{SiO}_{2}$-supported Pd NPs electrode. For Pd-Au bimetallic NPs, a constant potential of $-1.3 \mathrm{~V}$ (versus $\mathrm{Ag} / \mathrm{AgCl}$ ) was applied to the $\mathrm{n}^{+}-\mathrm{Si}_{\mathrm{SiO}} \mathrm{Si}_{2}$-supported $\mathrm{Pd}$ NPs electrode in an aqueous solution of $1 \mathrm{mM} \mathrm{KAuCl}_{4}$ in $0.1 \mathrm{M}$ potassium phosphate buffer at $\mathrm{pH}$ 3. Pd-Co bimetallic NPs were synthesized under $-1.8 \mathrm{~V}$ (versus $\mathrm{Ag} / \mathrm{AgCl}$ ) applied to the $\mathrm{n}^{+}-\mathrm{Si} / \mathrm{SiO}_{2}$-supported $\mathrm{Pd} \mathrm{NPs}$ electrode for $30 \mathrm{~min}$.

Characterization of $\mathbf{N C s}$ and $\mathbf{N P s}$ on $\mathbf{S i O}_{2}$. The NCs and $\mathrm{NPs}_{\text {s }}$ on $\mathrm{SiO}_{2}$ prepared in the manner described above were characterized by FESEM (Carl Zeiss, Germany) and EDS (Carl Zeiss, Germany) at the National Instrumentation Center for Environmental Management of Seoul National University. For high-resolution images, HRTEM (JEOL, Japan) and EDS (JEOL, Japan) were used at the UNIST (Ulsan National Institute of Science and Technology) Central Research Facilities Center (UCRF) of the UNIST. Focused ion beam (FEI, USA) milling was used to prepare the TEM specimens. Mo grids were used for the HRTEM-EDS analysis of Pd-Cu NCs. The average atomic percentage of Pd:Cu was 93.1:6.9 (Supplementary Fig. S11). The average atomic percentage of Pd:Au was 5.2:1 according to a quantitative analysis of Pd-Au NPs by FESEM-EDS (Supplementary Fig. S12). The average atomic percentage of Pd:Co in the Pd-Co NPs was 94.7:5.3 according to FESEM-EDS (Supplementary Fig. S13).

\section{References}

1. Velmurugan, J., Zhan, D. \& Mirkin, M. V. Electrochemistry through glass. Nat. Chem. 2, 498-502 (2010).

2. Chen, G. Z., Fray, D. J. \& Farthing, T. W. Direct electrochemical reduction of titanium dioxide to titanium in molten calcium chloride. Nature 407, 361-364 (2000).

3. Wang, H.-H. et al. Highly Raman-enhancing substrates based on silver nanoparticle arrays with tunable sub-10 nm gaps. Adv. Mater. 18, 491-495 (2006).

4. Gittins, D. I., Bethell, D., Schiffrin, D. J. \& Nichols, R. J. A nanometer-scale electronic switch consisting of a metal cluster and redox-addressable groups. Nature 408, 67-69 (2000).

5. Liu, C. \& Bard, A. J. Electrostatic electrochemistry at insulators. Nat. Mater. 7, 505-509 (2008).

6. Babcock, J. A. et al. Analog characteristics of metal-insulator-metal capacitors using PECVD nitride dielectrics. IEEE Electron Device Lett. 22, 230-232 (2001)

7. Morrison, S. R. Electrochemistry at Semiconductor and Oxidized Metal Electrodes. pp 304 (Plenum Press, New York, 1980).

8. Griscom, D. L., Brown, D. B. \& Sakes, N. S. in The Physics and Chemistry of

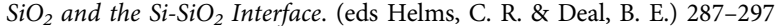
(Plenum, New York, 1988).

9. Nicollian, E. H., Berglund, C. N., Schmidt, P. F. \& Andrews, J. M. Electrochemical charging of thermal $\mathrm{SiO}_{2}$ films by injected electron currents. J. Appl. Phys. 42, 5654-5663 (1971).

10. Shkrob, I. A., Tadjikov, B. M., Chemerisov, S. D. \& Trifunac, A. D. Electron trapping and hydrogen atoms in oxide glasses. J. Chem. Phys. 111, 5124-5140 (1999).

11. Xiong, K., Robertson, J. \& Clark, S. J. Behavior of hydrogen in wide band gap oxides. J. Appl. Phys. 102, 083710-083713 (2007).

12. Schrauben, J. N. et al. Titanium and zinc oxide nanoparticles are protoncoupled electron transfer agents. Science 336, 1298-1301 (2012).

13. Revesz, A. G. On the mechanism of the ion sensitive field effect transistor. Thin Solid Films 41, L43-L47 (1977).

14. Bard, A. J., Parsons, R. \& Jordan, J. (eds) Standard Electrochemical Potentials in Aqueous Solution 39-48 (Marcel Dekker, New York, 1985).

15. Pineda, A. C. et al. The effect of network topology on proton trapping in amorphous $\mathrm{SiO}_{2}$. IEEE T. Nucl. Sci 48, 2081-2085 (2001).

16. van de Walle, C. G. Hydrogen as cause of doping in zinc oxide. Phy. Rev. Lett. 85, 1012-1015 (2000).

17. Gao, F. \& Goodman, D. W. Model catalysts: simulating the complexities of heterogeneous catalysts. Annu. Rev. Phys. Chem. 63, 265-286 (2012).

18. Farmer, J. A. \& Campbell, C. T. Ceria maintains smaller metal catalyst particles by strong metal-support bonding. Science 329, 933-936 (2010).

19. Tian, N., Zhou, Z.-Y., Sun, S. -G., Ding, Y. \& Wang, Z. L. Synthesis of tetrahexahedral platinum nanocrystals with high-index facets and high electrooxidation activity. Science 316, 732-735 (2007).

20. Zhang, X. G. Electrochemistry of Silicon and Its Oxide 3-93 (Kluwer Academic, New York, 2001)

21. Fisher, P. R., Daschbach, J. L., Gragson, D. E. \& Richmond, G. L. Sensitivity of 2nd-harmonic generation to space-charge effects at $\mathrm{Si}(111)$ electrolyte and $\mathrm{Si}(111) / \mathrm{SiO}_{2}$ electrolyte interfaces. J. Vac. Sci. Technol. A 12, 2617-2624 (1994).

22. Depas, M., Vermeire, B., Mertens, P. W., Meirhaeghe, R. L. V. \& Heyns, M. M. Determination of tunneling parameters in ultra-thin oxide layer poly-Si/SiO $/ 2 / \mathrm{Si}$ structures. Electronics 38, 1465-1471 (1995).

23. Rashkeev, S. N., Fleetwood, D. M., Schrimpf, R. D. \& Pantelides, S. T. Dual behavior of $\mathrm{H}^{+}$at $\mathrm{Si}_{-} \mathrm{SiO}_{2}$ interfaces: mobility versus trapping. Appl. Phys. Lett. 81, 1839-1841 (2002).

24. Vanheusden, K. et al. Non-volatile memory device based on mobile protons in $\mathrm{SiO}_{2}$ thin films. Nature 386, 587-589 (1997).

25. Gattrell, M., Gupta, N. \& Co, A. A review of the aqueous electrochemical reduction of $\mathrm{CO}_{2}$ to hydrocarbons at copper. J. Electroanal. Chem. 594, 1-19 (2006).

26. Kumar, B. et al. Photochemical and photoelectrochemical reduction of $\mathrm{CO}_{2}$. Annu. Rev. Phys. Chem. 63, 541-569 (2012). 
27. Arrington, D., Curry, M., Street, S., Pattanaik, G. \& Zangari, G. Copper electrodeposition onto the dendrimer-modified native oxide of silicon substrates. Electrochim. Acta 53, 2644-2649 (2008).

28. Salzemann, C. \& Petit, C. Influence of hydrogen on the morphology of platinum and palladium nanocrystals. Langmuir 28, 4835-4841 (2012).

29. Lee, J., Shim, W., Noh, J.-S. \& Lee, W. Design rules for nanogap-based hydrogen gas sensors. ChemPhysChem 13, 1395-1403 (2012).

30. Wang, D. \& Li, Y. Bimetallic nanocrystals: liquid-phase synthesis and catalytic applications. Adv. Mater. 23, 1044-1060 (2011).

31. Rodriguez, J. A. \& Goodman, D. W. The nature of the metal-metal bond in bimetallic surfaces. Science 257, 897-903 (1992).

32. Afanas'ev, V. V., Ciobanu, F., Pensl, G. \& Stesmans, A. Proton trapping in $\mathrm{SiO}_{2}$ layers thermally grown on $\mathrm{Si}$ and SiC. Solid State Electron. 46, 1815-1823 (2002).

33. Yokozawa, A. \& Miyamoto, Y. First-principles calculations for charged states of hydrogen atoms in $\mathrm{SiO}_{2}$. Phys. Rev. B 55, 13783-13788 (1997).

34. Sawy, E. N. E. \& Birss, V. I. Nano-porous iridium and iridium oxide thin films formed by high efficiency electrodeposition. J. Mater. Chem. 19, 8244-8252 (2009).

35. Vot, S. L., Roue, L. \& Belanger, D. Electrodeposition of iridium onto glassy carbon and platinum electrodes. Electrochim. Acta 59, 49-56 (2012).

36. Kim, S., Piao, L., Han, D., Kim, B. J. \& Chung, T. D. Surface enhanced raman scattering on non-SERS active substrates and in situ electrochemical study based on single gold microshell. Adv. Mater. 25, 2056-2061 (2013).

\section{Acknowledgements}

This work was supported by the Global Frontier R\&D Program on Center for Multiscale Energy System funded by the National Research Foundation under the Ministry of
Education, Science and Technology, Korea (number 2012M3A6A7055873), by the Nano Material Technology Development Program through the National Research Foundation of Korea (NRF) funded by the Ministry of Science, ICT and Future (number 20110030268), by the National Research Foundation of Korea (NRF) grant funded by the Korean government (MEST) (number 2012R1A2A1A03011289), and by the Center for Integrated Smart Sensors funded by the Ministry of Science, ICT \& Future Planning as Global Frontier Project (number CISS-2011-0031845). Mr Young-Ki Kim (Ulsan National Institute of Science and Technology (UNIST) Central Research Facilities Center, Ulsan, Korea) is gratefully acknowledged for conducting the HRTEM characterization.

\section{Author contributions}

T.D.C. and J.-Y.L. designed the study and wrote the paper, J.-Y.L. performed the electrochemical experiments and collected data, J.G.L. conducted a portion of the electrochemical experiments and $\mathrm{CO}_{2}$ reduction; M.S. prepared the bimetallic NCs, S.-H.L. and Y.J.P. fabricated and evaluated the $\mathrm{Si} / \mathrm{SiO}_{2}$ electrodes, L.P. recorded the SERS spectra, and J.H.B. and S.Y.L. assisted with the impedance analysis. All of the authors discussed the results and commented on the manuscript.

\section{Additional information}

Competing financial interests: The authors declare no competing financial interests.

Reprints and permission information is available online at http://npg.nature.com/ reprintsandpermissions/

How to cite this article: Lee, J.-Y. et al. Hydrogen-atom-mediated electrochemistry. Nat. Commun. 4:2766 doi: 10.1038/ncomms3766 (2013). 